\title{
Development and implementation of a recruitment strategy to better identify people 'at risk' for cardiovascular disease for human dietary intervention studies
}

\author{
E. M. Bachmair ${ }^{1}$, I. Ford ${ }^{2}$ and B. de Roos ${ }^{1}$ \\ ${ }^{1}$ Rowett Institute of Nutrition \& Health, University of Aberdeen, Aberdeen AB21 9SB, UK and ${ }^{2}$ School of Medicine \& \\ Dentistry, University of Aberdeen, Aberdeen AB25 2ZD, UK
}

The recruitment of asymptomatic subjects 'at risk' of cardiovascular disease (CVD) is often a critical step in the design of human studies that assess modulation of CVD outcomes through dietary intervention. Indeed, such volunteers are often more likely to show subtle beneficial changes in CVD risk factors following dietary intervention ${ }^{(1)}$. Generally, being 'at risk' is based on having one or more individual risk factors. However, CVD is a multi-factorial disease and as risk factors can interact ${ }^{(2)}$. CVD risk scores are recommended in the clinical setting to identify those at high risk of CVD, and to direct their therapy ${ }^{(3)}$, but are hardly used during the recruitment process.

A modular two-step recruitment strategy based on the ASSIGN risk score ${ }^{(4)}$, in combination with individual risk factors, was developed and subsequently implemented for the volunteer recruitment for a human intervention study. We investigated whether such a recruitment strategy, compared with the use of individual conventional risk factors, could lead to an improved and consistent identification of the appropriate study population for dietary studies.

\begin{tabular}{|c|c|c|c|c|c|c|c|c|c|c|c|c|}
\hline \multirow[b]{2}{*}{ No } & \multirow[b]{2}{*}{ Sex } & \multirow{2}{*}{$\begin{array}{l}\text { Age } \\
{[y]}\end{array}$} & \multirow{2}{*}{$\begin{array}{c}\text { BMI } \\
{\left[\mathrm{kg} / \mathrm{m}^{2}\right]}\end{array}$} & \multirow{2}{*}{$\begin{array}{c}\text { BPsys } \\
{[\mathrm{mmHg}]}\end{array}$} & $\mathrm{TC}$ & HDL & TAG & Glucose & \multirow[b]{2}{*}{ FH } & \multirow{2}{*}{$\begin{array}{c}\text { ASSIGN } \\
{[\%]}\end{array}$} & \multicolumn{2}{|c|}{ Eligibility } \\
\hline & & & & & & & $\overline{\mathrm{ol} / \mathrm{l}]}$ & & & & Individual factors & Risk score strategy \\
\hline$\overline{1}$ & $\hat{o}$ & 35 & 26.3 & 148 & 5.88 & 1.0 & 1.9 & 4.8 & $\checkmark$ & 9.8 & $x$ & $\checkmark$ \\
\hline 2 & $\hat{o}$ & 40 & 28.3 & 140 & 5.61 & 1.1 & 1.6 & 4.8 & $\checkmark$ & 8.7 & $x$ & $\checkmark$ \\
\hline 3 & $\hat{o}$ & 42 & 24.2 & 135 & 4.55 & 0.9 & 0.8 & 5.7 & $\checkmark$ & 8.1 & $x$ & $\checkmark$ \\
\hline 4 & q & 43 & 29.4 & 120 & 4.36 & 1.2 & 0.9 & 4.4 & $x$ & 3.4 & $x$ & $\checkmark$ \\
\hline 5 & 우 & 48 & 26.2 & 155 & 4.56 & 2.0 & 2.1 & 5.1 & $x$ & 3.5 & $\checkmark$ & $\checkmark$ \\
\hline 6 & $\hat{\jmath}$ & 55 & 27.8 & 155 & 5.89 & 1.0 & 2.3 & 5.3 & $\checkmark$ & 22.9 & $\checkmark$ & $x$ \\
\hline 7 & $\hat{\jmath}$ & 55 & 23.6 & 140 & 4.92 & 0.8 & 0.8 & 5.9 & $\checkmark$ & 17.7 & $x$ & $\checkmark$ \\
\hline 8 & q & 57 & 22.8 & 130 & 5.82 & 1.3 & 1.8 & 6.1 & $x$ & 7.6 & $x$ & $\checkmark$ \\
\hline 9 & $\begin{array}{l}+ \\
\text { Q }\end{array}$ & 60 & 24.8 & 125 & 5.56 & 0.9 & 2.0 & 4.9 & $x$ & 10.6 & $x$ & $\checkmark$ \\
\hline 10 & $\hat{\jmath}$ & 65 & 23.5 & 120 & 5.28 & 1.3 & 1.5 & 6.0 & $x$ & 14.1 & $x$ & $\checkmark$ \\
\hline
\end{tabular}

BPsys, systolic blood pressure; TC, fasting plasma total cholesterol; TAG, triacylglycerol; Glucose, detection of impaired glucose tolerance defined as 5.6-6.9 mmol/l fasting glucose levels; FH, family history; $\hat{o}$, male; , female; $\boldsymbol{V}$, yes; $\boldsymbol{X}$, no.

Incorporation of the ASSIGN score in the recruitment strategy led to the inclusion of three subjects with a score of 10-20\% (intermediate risk), and six subjects with a score of $<10 \%$ (low risk), but having at least one additional risk factor such as age $>50 \mathrm{yrs}, \mathrm{BMI}>25 \mathrm{mg} / \mathrm{kg}^{2}$, impaired glucose tolerance or elevated TAG levels. Subject recruitment based on an individual traditional risk factor based approach resulted in only two eligible volunteers, and would have failed to detect that subject 6 was 'at high risk' and should be referred to a GP for further assessment. In conclusion, our ASSIGN risk score-based recruitment strategy, compared with the use of individual risk factors, was found to enhance the identification of eligible asymptomatic subjects, and may represent a more robust and uniform approach to identify the appropriate 'at risk' study population. A modular concept of a recruitment procedure can be used to facilitate the application for various recruitment strategies.

E.M. Bachmair receives a scholarship partially funded by Lipid Nutrition. The Rowett Institute of Nutrition and Health is funded by the Scottish Government Rural and Environment Science and Analysis Services (RESAS).

1. Sanderson P, Olthof M, Grimble RF et al. (2004) Br J Nutr 91, 491-500.

2. Cooney MT, Dudina A, D'Agostino R et al. (2010) Circulation 122, 300-310.

3. Wood D, Wray R, Poulter N et al. (2005) Heart 91 SUPPL. 5, V1-V53.

4. Woodward M, Brindle P and Tunsfall-Pedoe H (2007) Heart 93, 172-176. 